\title{
Vertical Integration of Agricultural products supply chain and quality Safety of Agricultural products
}

\author{
Yan $\mathrm{Li}^{1 *}$, Cong Jing Zhang ${ }^{2 *}$ \\ ${ }^{1}$ Harbin University of Commerce, Theoretical Economics, Song Bei District, Harbin, Heilongjiang, China \\ ${ }^{2}$ Harbin University of Commerce, Industrial Economics, Song Bei District, Harbin, Heilongjiang, China
}

\begin{abstract}
Today, food safety is a common concern in the world. As the main source of food, agricultural products' safety is also worthy of attention. By establishing the vertical integration model of the agricultural product supply chain, the circulation links of agricultural products can be reduced, and the circulation efficiency and quality level of agricultural products can be improved. This paper assumes that under the condition of simple fresh agricultural products, there is only one wholesaler and one retailer in the agricultural product supply chain. Through the analysis of the economic model, it is concluded that the vertical integration of the agricultural product supply chain has a positive impact on the safety of agricultural products. With the improvement of the vertical integration of the supply agricultural products supply chain, the efforts of wholesalers and suppliers to ensure the safety of agricultural products have been improved, the circulation cost of agricultural products has been reduced, and the sales price of agricultural products has been reduced.
\end{abstract}

\section{Introduction}

There are many circulation organizations and complicated links in the supply chain of agricultural products. The circulation cost of agricultural products is high, and the responsibility of the organization to ensure the safety of agricultural products is dispersed. The main causes of these problems include excessive circulation links, running a bulk tissue, non-strict regulatory, and low organological supply chain. How to avoid these issues, improve the quality and safety of agricultural products while reducing unnecessary costs? This paper has been studied from the perspective of the agricultural supply chain.

Vertical integration means that an enterprise realizes more than two successive links in the process of production, circulation, and products. Mighell Ronald LJ Lawrence A Jones and Aruoma regard the coordination among the production, processing, storage, transportation, sale, and other links of agricultural products as the vertical coordination of the agricultural supply chain [1-2]. At the same time, many scholars also have more research on the impact of the longitudinal integration of agricultural industrial chain farm products. Through the analysis and comparison of the development of the beef industry, John M. Crespi and TinaL believe that vertical integration has been proved to have important progress in improving the efficiency of the agricultural supply chain, but the impact varies with time and commodities, and the development of the industry should develop in the direction of greater integration [3]. Through the analysis of the vertical integration of production, processing, and sales in the American pork supply chain, James B.Kliebenstein and John D.Lawrence finds that vertical integration promotes the competitive position of the main body in the market and promotes the development of the regional industry Sporleder TL, WuSY [4-5]. From the perspective of new social economics, it is found that the agricultural product supply chain has some special properties compared with other products. The vertical cooperation and social capital of the agricultural product supply chain improve the level of trust between the agricultural product circulation subjects and reduce the opportunistic behavior that may exist in the transaction between the two parties.

Also, the quality and price of agricultural products are related to the agricultural supply chain structure. Gerrit Willem Ziggers and Jacques Trienekens believe that the motivation of vertical cooperation in the agricultural supply chain is the characteristics of both product and market. And the close connection between the product supply chain circulation main body can make the product quality guaranteed, and the actual competitiveness is improved [6]. It can be seen that the existing literature on the agricultural industry chain is more in-depth, these studies provide a valuable reference for the study of this paper. From the point of view of agricultural product wholesalers and retailers, through the analysis of the economic model, this paper further discusses the significance of the supply chain to the reform of the agricultural product circulation system and puts forward relevant feasible suggestions. 


\section{Materials and Methods}

Suppose 1: Suppose that there is only one wholesaler and retailer in the agricultural product supply chain, who are rational and aim to maximize their profits. The purchase of agricultural products by end-consumers depends on the price of agricultural products and the level of quality and safety.

Suppose 2: The price of the wholesaler to the retailer for a unit of production is $\bar{p}$; The wholesaler's cost per unit of production is $\bar{c}$. Wholesalers ensure the cost $m$ increased by the quality and safety level of agricultural products, such as preservation, packaging, testing.

Suppose 3: The sales price of the retailer unit agricultural product is $\bar{p}^{\prime}$; The transportation cost of retailer purchase unit agricultural products is $\vec{c} ; \bar{p}^{\prime}>\bar{p}$.

Suppose 4: In this model, the quality and safety judgment of agricultural products is based on the extent to ensure the quality and safety of agricultural product quality, and the retailer does not change the quality of agricultural products. $\eta$ indicates the degree of efforts made by wholesalers for the quality level of agricultural products, $0<\eta<1$. When the agricultural product wholesaler does not take corresponding measures for agricultural product quality and safety, $\eta=0$; In ensure the strength of the agricultural product quality and safety, the greater the effort, the higher the cost.

Suppose 5: The market demand of agricultural products is affected by sales prices, agricultural quality, and safety,

$Q=\alpha-\beta p+\chi \eta+\varepsilon, \alpha$ represents the market size, $\beta$ represents the sensitivity of demand to price; $\alpha$ and $\beta$ are greater than 0 and constant; $\chi$ indicates the impact of the quality and safety of agricultural products on demand, that is, the degree of efforts made by agricultural wholesalers to ensure the quality and safety of agricultural products. $\eta_{\text {for every } 1 \% \text { increase, the }}$ market demand for agricultural products increases; $\varepsilon$ describes the fluctuation of market demand, with an average of 0 .

Suppose 6: The circulation link is integrated, and the wholesale market and retailers are organized and become the main body. The acquisition, wholesale and retail of agricultural products are carried out by the industrialization leading agriculture, the vertically integrated production flow can achieve information sharing, and the quality of agricultural products can be traced back to supervision.

Suppose 7: In the vertical integration of agricultural circulation main body, the value-added links such as the brand building are not considered, and only the agricultural products will carry out longitudinal integration construction between the flow of agricultural products in the wholesale market and retailers.

Suppose 8: After integrated agricultural sales price is $p$, industrialized leading agriculture gaining unit production of agricultural products $c$, large-scale procurement unit costs less than the wholesale market purchase cost, $c<\bar{c}$.
When the wholesaler and the retailer of agricultural products are not integrated, the wholesaler and the retailer of agricultural products, as independent interest subjects, will make decisions according to the maximization of their interests. The wholesaler is the dominant player in the supply chain, and the retailer is the follower. The wholesaler takes decisions based on the information it has and the principle of maximizing profits. On this basis, the retailer offers a retail price that is in line with its interests. According to backward induction, the retailer's decision is considered first.

The profit function of the retailer is:

$$
\bar{\pi}^{\prime}=\left(\bar{p}^{\prime}-\bar{p}-\vec{c}\right) Q=\left(\bar{p}^{\prime}-\bar{p}-\vec{c}^{\prime}\right)\left(\alpha-\beta \bar{p}^{\prime}+\chi \eta\right)
$$

According to profit maximization requirements:

$$
\begin{gathered}
\frac{\partial \bar{\pi}^{\prime}}{\widetilde{p}^{\prime}}=\alpha-2 \beta \vec{p}^{\prime}+\chi \eta+\bar{p} \beta+\vec{c} \beta=0 \\
\bar{p}^{\prime}=\frac{\alpha+\chi \eta+\beta \bar{p}+\vec{c}^{\prime} \beta}{2 \beta}
\end{gathered}
$$

The profit function of the wholesaler is

$$
\bar{\pi}=(\bar{p}-\bar{c}-\eta m) Q=(\bar{p}-\bar{c}-\eta m)\left(\alpha-\beta \bar{p}^{\prime}+\chi \eta\right)
$$

According to profit maximization requirements

$$
\begin{gathered}
\frac{\partial \bar{\pi}}{\partial \bar{p}}=\frac{1}{2}(\alpha+\chi \eta-2 \beta \bar{p}+\eta m \beta)=0 \\
\frac{\partial \bar{\pi}}{\partial \eta}=\frac{1}{2}(\chi \bar{p}-\chi \bar{c}-\alpha k-2 m \chi \theta+\beta m \hat{p}+\beta m \bar{c})=0 \\
\bar{p}=\frac{m(\alpha-\bar{c} \beta)-\chi \bar{c}}{\beta m-\chi} \\
\eta=\frac{\alpha-2 \beta \bar{c}}{\beta m-\chi} \\
\bar{p}^{\prime}=\frac{2 \alpha m-3 \chi \bar{c}-\beta m \bar{c}+(\beta m-\chi) \bar{c}}{\beta m-\chi}
\end{gathered}
$$

Under the vertical integration construction mode, part of the market mechanism is replaced by the powerful agricultural product leading enterprises through the organization of vertical integration, the agricultural product circulation link is simplified, and the agricultural product circulation is carried out by the agricultural product leading enterprises. At this time, the profit function is

$$
\pi=(p-c-\eta \eta)(\alpha-\beta p+\chi \eta)
$$

According to profit maximization requirements:

$$
\begin{gathered}
\frac{\partial \pi}{\partial p}=\alpha-2 \beta p+\chi \eta+m \beta \eta+c \beta=0 \\
\frac{\partial \pi}{\partial \eta}=\chi p-\chi c-m \alpha+m \beta p-2 m \eta \chi=0 \\
p=\frac{\alpha m-\chi c}{\beta m-\chi}
\end{gathered}
$$




$$
\eta=\frac{\alpha-\beta c}{\beta m-\chi}
$$

\section{Results \& Discussion}

In this paper, under the condition of simple fresh agricultural products, an analysis of the influence of a supply chain model composed of a wholesaler and a retailer on the vertical integration of the supply chain of agricultural products and the efforts of agricultural products sales prices and circulation subjects to ensure the quality and safety of agricultural products. First of all, reducing the circulation of agricultural products can reduce costs and the final sales price of agricultural products. When the wholesaler and the retailer do not form a combination for integration, the circulation prices of agricultural products are respectively (7) and (9). However, as wholesalers and suppliers combine, agricultural prices change. The price of agricultural products changed to (12). Compared with the previous price, the price of agricultural products after the combination is larger than the price of (7) before but less than the price of (9). The agricultural product circulation is reduced, saving a lot of unnecessary cost spending, meaning that consumers can purchase agricultural products at a lower price, improve their consumers. The less the flow of agricultural products, the decrease in circulation cost, the lower the price of agricultural products. Second, the more agricultural circulation, the lower the agricultural product circulation main body to ensure the safety of agricultural products, the less absolute improvement of agricultural safety issues. When the wholesaler and the retailer shave been combined, the efforts of the agricultural product circulation subjects have made great efforts to improve the quality of agricultural products, $(14)>(8)$. It shows that with the improvement of the degree of vertical integration of agricultural products supply chain, the higher the efforts made by agricultural products circulation subjects to ensure the safety of agricultural products, the more likely they are to provide safe agricultural products. It is worth noting that the agricultural products sold by retailers often come from multiple wholesalers, and the competition among multiple wholesalers may have an effect on the quality influencing the decision of the main agricultural products in the agricultural supply chain, so the model in this paper has some limitations.

Table 1. Comparison of Agricultural Supply Chain Related Data

\begin{tabular}{|c|c|c|}
\hline \multirow{2}{*}{$\begin{array}{c}\text { Agricultural } \\
\text { products } \\
\text { supply chain }\end{array}$} & Before the combination & $\begin{array}{c}\text { After the } \\
\text { combination }\end{array}$ \\
\cline { 2 - 3 } & $\bar{p}=\frac{m(\alpha-\bar{c} \beta)-\chi \bar{c}}{\beta m-\chi} \bar{p}^{\prime}=\frac{20 m-3 \bar{c}-\beta m \bar{c}+(\beta m-\chi) \bar{c}}{\beta m-\chi}$ & $p=\frac{\alpha m-\chi c}{\beta m-\chi}$ \\
\hline$p$ & $\frac{\alpha-2 \beta \bar{c}}{\beta m-\chi}$ & \\
\hline$\eta$ & & $\frac{\alpha-\beta c}{\beta m-\chi}$ \\
\hline
\end{tabular}

\section{Conclusions}

The vertical integration of the agricultural products supply chain studied in this paper is hoping to provide some references and suggestions for the construction of agricultural products circulation system and the improvement of agricultural products circulation problems. Through the comparative analysis of the agricultural product circulation model without vertical integration and the vertical integration construction circulation model, it can be concluded that after vertical integration, the final retail price of agricultural products in the agricultural supply chain is lower than that without vertical integration. The degree of effort of the circulation subject in the agricultural product supply chain to ensure the safety of agricultural products is higher than that of the circulation subject in the mode of vertical integration to ensure the safety of agricultural products.
At the same time, according to the research of this paper, some suggestions on the circulation of agricultural products are put forward. First of all, the relevant departments should strengthen the information network construction of the agricultural products supply chain and establish a unified agricultural products supply chain information exchange service platform. Second, we should pay attention to the development of leading enterprises in the agricultural products supply chain and promote the development of modern logistics of agricultural products. At the same time, it is worth noting that the agricultural product supply chain model discussed in this paper mainly refers to the supply chain model of simple fresh agricultural products, and there is a lack of relevant research on empirical data in the model, so further quantitative analysis needs further research. 


\section{References}

1. Ronald L. Mighell, Lawrence A Jones. (1963) Vertical Coordination in Agriculture. USDA-ERS AGEC Report, Washington.

2. Aruoma O I. (2006) The Impact of Food Regulation on the Food Supply Chain. Toxicology, 221: 119-127.

3. John M. Crespi, Tina L. (2018) Are Cattle Markets the Last Frontier? Vertical Coordination in Animal-Based Procurement Markets. Saitone.Annual Review of Resource Economics, 10: 207-227.

4. James B. Kliebenstein, John D. (1995) Contracting and Vertical Coordination in the United States Pork Industry. LawrenceAmerican Journal of Agricultural Economics, 77:1213-1218.

5. Sporleder T, Wu S. (2006). Social capital and vertical ties in agrifood supply chain. Journal on Chain and network science, 1: 1-7.

6. Ziggers GW, Trienekens J. (1999) Quality assurance in food and agribusiness supply chains: Developing successful partnership. Production Economics, 60: 271-279. 